Environmental Biology of Fishes, 2003, v.67, n.2, pp.157-168.

Print ISSN: 0378-1909

Online ISSN: 1573-5133

DOI: 10.1023/A:1025686310020

The original publication is available at www.springerlink.com

http://springerlink.metapress.com/content/r88608116812219v/?p=383a52cc684b474d84422c7f544dd080e\&pi=3

(C) 2003 Kluwer Academic Publishers. Printed in the Netherlands.

\title{
Individual growth and foraging responses of age-0 largemouth bass to mixed prey assemblages during winter
}

\author{
Stephanie M. Micucci, James E. Garvey, Russell A. Wright \& Roy A. Stein \\ Aquatic Ecology Laboratory, Department of Evolution, Ecology, and Organismal Biology, \\ The Ohio State University.
}

\begin{abstract}
Synopsis
We conducted an outdoor pool experiment at a mid-temperate latitude $\left(\mathrm{Ohio}, 40^{\circ} \mathrm{N}\right)$ to determine how commonly occurring prey assemblages affect individual foraging and growth of individually marked, age- 0 largemouth bass during winter. The treatments were low prey, bluegill prey only, macroinvertebrates only, and bluegill plus macroinvertebrates. Across all treatments, growth in mass $(\mathrm{g})$ was unrelated to body size. Conversely, small individuals lost more energy $(\mathrm{kJ})$ than large counterparts in all but the macroinvertebrate-only treatment. With low prey, overall growth of largemouth bass was negative, with losses varying among individuals by $30 \%$ and $60 \%$ for mass and energy content, respectively. Counterparts in bluegill-only pools also consistently lost mass and energy, with less variability (15\% mass; $30 \%$ energy). In the macroinvertebrate-only treatment, $31 \%$ of individuals gained mass, reflecting the greatest range in mass $(100 \%)$ and energy $(60 \%)$ change. With macroinvertebrates plus bluegill, overall growth was generally negative, with intermediate variance among individuals. Variation in growth among individuals typically increased with the frequency that prey occurred in diets during sampling. Apparently, some individuals were inactive, foraged infrequently, and consistently lost intermediate quantities of mass and energy. Others were active and foraged with variable success. Because activity and growth vary among individuals as a function of prey composition during winter, prey assemblages during this season will affect patterns of firstyear survival and cohort strength.
\end{abstract}

\section{Introduction}

Ecologists have long recognized that phenotypic variation among individuals influences their collective effects on population, community, and ecosystem processes (e.g. Judson 1994, Brown 1995). This is particularly relevant for species that experience high mortality during early life, in which exceptional individuals rather than average ones survive (Crowder et al. 1992, Chambers \& Trippel 1997, Cowan et al. 2000). To effectively forecast population dynamics of these species and their potential ecosystem effects, we must identify characteristics that vary among individuals during early life and determine how they influence survival during critical times when mortality is high and cohort strength is set (i.e. recruitment occurs).

At temperate latitudes, winter critically affects the first-year survival of many fish (Garvey et al. 1998a). As temperatures decline during fall, food becomes scarce. Hence, many species reduce feeding and undergo torpor, presumably to minimize energetic costs. Winter torpor should only occur if the expected net energy loss of remaining active and searching for prey exceeds that of becoming inactive and catabolizing energy stores (Shul'man 1974, Cargnelli \& Gross 1997, Foy \& Paul 1999). This scenario is typical in north temperate ecosystems, in which foraging during winter is extremely costly due to constant, cold temperatures, and scarce prey (Fullerton et al. 2000).

At mid-temperate latitudes, how winter conditions affect foraging activity and thereby the 
growth and survival of individual fish may be more complex. Winter temperatures vary tremendously both within and among years. Food availability can be driven by the effect of winter temperatures on prey survival (Adams et al. 1982a,b, Baldwin et al. 2000). And prey assemblages may vary widely in their size and energetic value. As such, winter foraging decisions within mid-temperate systems may depend on an individual's ability to assess the relative risks of remaining inactive or foraging with variable environmental conditions (Krebs \& Kacelnik 1984). This decision is likely influenced by the energetic condition of the forager as well as the mean and variability of prey abundance. For example, risk-sensitivity theory predicts that an individual with abundant energy reserves may remain inactive if the expected foraging return is highly variable (Smallwood \& Cartar 1996). Foraging should only commence under variable prey conditions if energy reserves are nearly exhausted. If food is abundant and temperatures are sufficient to foster growth, fish should forage during winter, regardless of condition.

Largemouth bass, Micropterus salmoides, is a widely distributed fish that is abundant within mid-latitude $\left(35-40^{\circ} \mathrm{N}\right)$ lakes in North America. Although this species has been suggested to undergo an obligatory torpor during winter (Crawshaw 1984), winter-simulation experiments have demonstrated that age-0 largemouth bass will forage actively and grow at mid-temperate latitudes when prey are abundant and available (Garvey et al. 1998a, Wright et al. 1999, Fullerton et al. 2000). Growth, condition, and survival of age-0 largemouth bass differ among ponds and lakes during winter (Toneys \& Coble 1979, Garvey et al. 1998a), suggesting that prey availability and perhaps foraging decisions vary among systems. Differences in individual success during winter have been attributed to body size for many species including age-0 largemouth bass, in which large individuals are more likely to survive than small counterparts (Gutreuter \& Anderson 1985, Garvey et al. 1998a).

We hypothesized that feeding activity, growth, and survival of age-0 largemouth bass at mid-temperate latitudes during winter depend on temperature, prey assemblage structure, and body size. To test these hypotheses, we conducted an experiment in outdoor pools with individuals exposed to their typical prey assemblages during a winter in Ohio, U.S.A. We predicted that largemouth bass with low prey abundance (i.e. low zooplankton densities) should become inactive, using energy reserves to survive winter. With macroinvertebrate assemblages, patterns of foraging and growth should vary because these assemblages are generally dominated (in density) by small-bodied taxa, with rarely occurring, large (and energy-rich) individuals (Garvey et al. 1998b). Because age-0 bluegill, Lepomis macrochirus, are often preferred by age0 largemouth bass over macroinvertebrates, they should provide a high-energy return (Olson 1996a,b). As such, largemouth bass overlapping with these assemblages should forage and grow during winter. Largemouth bass co-occurring with bluegill plus macroinvertebrates should grow most quickly with the least variability among individuals, given high prey availability. Across all treatments, foraging and growth should decline with declining daily temperature (Fullerton et al. 2000). Large individuals should forage more successfully and lose less energy than small counterparts (Post \& Evans 1989). Patterns emerging from this experiment will provide insight into how individual responses to prey assemblage structure influence survival and cohort strength during a period thought to be characterized by inactivity.

\section{Materials and methods}

In October 1996, we collected age-0 largemouth bass from Clark Lake, Ohio, (Clark County, Ohio) using a pulsed-DC electrofishing boat. Bluegills were collected from Hebron 
State Fish Hatchery, Hebron, Ohio in November1996. We used 20 outdoor pools ( 26501) at the Aquatic Ecology Laboratory, Ohio State University with ambient temperatures, aeration, and flow-through, dechlorinated city water for our experiment. Sand and leaf litter were in 12 of 20 pools. Although these 12 pools had an extant assemblage of macroinvertebrates including snails, leeches, and oligochaetes, they were inoculated with zooplankton and macroinvertebrates both from West Campus Pond, Ohio State University campus and Hebron State Fish Hatchery ponds. We added terrestrial leaf litter to the remaining eight pools without bottom sediments to provide cover.

Largemouth bass were divided into five, 20-mm length classes $(60-160 \mathrm{~mm}$ total length, TL); each individual within each pool received a unique pelvic fin (right or left), pectoral fin (right or left), or dorsal spine clip. One largemouth bass per length class was randomly assigned to each of 16 pools ( $\mathrm{N}=5$ largemouth bass per pool), with one of four prey treatments: (1) low prey (LOW), (2) bluegills (BG), (3) macroinvertebrates (MI), or (4) macroinvertebrates + bluegills (MIBG). Bluegills ( $\mathrm{N}=25 / \mathrm{pool}$ ) were stocked on 25 November 1996 (mean wet mass (g) per pool $\pm 1 \mathrm{SE}=6.8 \pm 0.3$ ) and again on 25 January 1997 (mean wet mass $11.2 \pm 0.6$ ). Stocked bluegills in each pool were comprised of 8 small $(16-27 \mathrm{~mm}), 7$ medium $(28-35 \mathrm{~mm})$, and 10 large $(36-50 \mathrm{~mm})$ individuals. Although our intent with the LOW treatment was to completely restrict prey abundance, zooplankton and invertebrates did occur at low densities, reducing but not completely halting largemouth bass consumption. To determine macroinvertebrate changes without largemouth bass, we added a bluegill plus macroinvertebrate (NOBASS) treatment ( $\mathrm{N}=4$ pools). After each stocking event, a subset of bluegill representative of the size and quantity used in each bluegill prey replicate was handled in the same manner as stocked prey fish and held in a pool to assess prey fish mortality. After $24 \mathrm{~h}$, survival of bluegills was $100 \%$ and $90 \%$, respectively for the two stocking events. A size-stratified subset of largemouth bass $(\mathrm{N}=15)$ and bluegill $(\mathrm{N}=20)$, representative of sizes used in the experiment, was reserved to quantify initial energy densities (per methods below).

The experiment began 25 November 1996 and ended 1 April 1997. We sampled 3-5 largemouth bass from pools about every 4 weeks (unless prevented by extreme weather) with a backpack pulsed-DC electrofisher. We identified each largemouth bass, measured (nearest $1 \mathrm{~mm}$ $\mathrm{TL}$ ) and weighed (nearest $0.1 \mathrm{~g}$ wet mass) it, and collected stomach contents using gastric lavage (Seaburg 1957). Stomach contents were stored in fine-mesh bags and preserved in $95 \%$ ethanol. Largemouth bass were then returned to their respective pools. At experiment's end, we drained the pools, collected 76 (of 80) surviving largemouth bass, placed them on ice, then weighed, measured, and froze them. One dead fish was recovered. Temperatures during the experiment were recorded 10 times daily in two pools with HoboTemp data loggers.

One to two days before largemouth bass sampling, we suctioned sediments plus water from two random locations in each pool with a PVC pipe $(120 \mathrm{~cm}$ length $\times 20 \mathrm{~cm}$ diameter $)$ and an industrial wet/dry vacuum for 10s (Garvey et al. 1998a) to estimate macroinvertebrate biomass. Each sample was sieved (mesh size $=456 \mu \mathrm{m}$ ), stored in an airtight container, and refrigerated. Organisms were sorted and preserved in 95\% ethanol. Diet and benthic organisms were identified at least to Order, and Family when possible; total biomass (dry mass, mg) was estimated using body dimension-weight relationships (macroinvertebrates: Smock 1980, G.G. Mittelbach, Kellogg Biological Station, Michigan State University, unpublished data; zooplankton: Dumont et al. 1975). Using a dissecting microscope at $25 \times$ power with digitizing equipment (SigmaScan 1992, 1998), we measured appropriate body dimensions (e.g. body length, head width) for each regression and converted each measurement to wet mass (see 
Garvey et al. 1998a).

We estimated dry mass and energy content $(\mathrm{kJ})$ of individual largemouth bass by drying for 3-10 days at $60-65^{\circ} \mathrm{C}$. Individuals were then ground to a powder with a Wiley Mill, dried again for 3 days and combusted with a Parr oxygen bomb calorimeter.

\section{Statistical analysis}

Unless otherwise stated, all analyses were conducted using SAS (Type III sums of squares; SAS 1990). We considered alphas $<0.05$ significant and those $<0.1$ or $\geq 0.05$ marginally significant. For each treatment, we generated linear regressions of TL versus mass and TL versus energy content at the beginning and end of the experiment. With analysis of covariance (ANCOVA), we explored how mass and energy content changed as a function length (the covariate) and time. All data were $\log _{\mathrm{e}} X$-transformed before analyses.

To determine how macroinvertebrate biomass changed through time, we used a repeated measures analysis of variance (GLM Procedure; SAS 1990). The response variable was total biomass estimated from cores taken in each pool. We also used a repeated measures ANOVA to determine how the proportion of empty stomachs changed among treatments through time. Multivariate analysis of variance (MANOVA) was used to examine relative contributions of prey types by biomass to largemouth bass diets as a function of treatment. The three dependent variables in the MANOVA model were mean wet masses of bluegill, macroinvertebrate, and zooplankton in diets (GLM Procedure; SAS 1990). These means were first generated among individuals within each pool, and then averaged across the four sampling dates. We also determined if the occurrence of fish in diets was related to body size with a G-test comparing the frequency of bluegills in small $(<100 \mathrm{~mm})$ and large $(\geq 100 \mathrm{~mm})$ largemouth bass against the null expectation (Sokal \& Rohlf 1995).

Because we followed individuals through the experiment, we explored individual-based patterns of growth and foraging patterns. Proportional changes in wet mass and total energy of individual largemouth bass were calculated as (final - initial)/initial. For the sub-sample of fish at the start of the experiment, TL was a strong predictor of total kJ (see Table 1). Hence, we calculated initial energy quantities for individual large-mouth bass using initial TL. We regressed change in wet mass against change in energy content to determine how these two growth quantities were related. From a previous experiment conducted during winter 1995-1996 (Garvey et al. 1998a), we expected that LOW age-0 largemouth bass during winter would lose both energy content and mass and included these data in our analysis for comparison.

We hypothesized that each largemouth bass might adopt one of two strategies during winter - forage actively or become inactive. The presence of food in stomachs was used to infer whether each individual fish was foraging or inactive. We calculated a foraging activity index as the proportion of days that each individual largemouth bass was captured (up to four dates) with prey in its stomach. This index was plotted against proportional change in mass and energy content across all treatments. We used a two-dimensional Kolmogorov-Smirnov (2DKS) test (see Garvey et al. 1998c) to test the null hypothesis that variance in growth was unrelated to foraging activity. The 2DKS test compares the observed joint distribution of densities to one expected if densities occurred independently (Fasano \& Franceschini 1987, Press et al. 1992, Garvey et al. 1998c). Each test generated a test statistic, D, representing the maximum point of departure between the observed and expected distributions. Often, this point represents a threshold change in variance in the distribution (Garvey et al. 1988c). To determine the significance for each test, we then rerandomized the observed X,Y pairs 5000 times (Manly 
1991), determining the proportion of randomly generated Ds exceeding the actual test statistic. If this proportion exceeded 0.1 , we concluded that the observed pattern was generated by chance. At the point of maximum departure (i.e. threshold change in variance at some activity value) within each bivariate distribution, we compared the mean and variance of change in mass and energy content with a t-test and F-test, respectively, to further explore differences in the distributions (SAS univariate procedure; SAS 1990).

Table 1. Linear regression results of total length (TL, mm) versus mass ( $\mathrm{g}$ ) and TL versus total energy (kJ) of largemouth bass in outdoor pools at the Ohio State University, Aquatic Ecology Laboratory during winter 19961997.

\begin{tabular}{lllllll}
\hline $\begin{array}{l}\text { Dependent } \\
\text { variable (Y) }\end{array}$ & Treatment & $\begin{array}{l}\text { Sampling } \\
\text { time }\end{array}$ & $\mathrm{N}$ & $\mathrm{a}$ & $\mathrm{ln}(\mathrm{b})$ & $\mathrm{R}^{2}$ \\
\hline Mass & LOW & Start & 20 & 3.40 & -13.3 & 0.99 \\
& & End & 20 & 3.48 & -13.8 & 0.98 \\
& BG & Statt & 19 & 3.13 & -12.2 & 0.99 \\
& & End & 19 & 3.15 & -12.1 & 0.98 \\
& MI & Start & 19 & 3.26 & -12.6 & 0.99 \\
& MIBG & End & 19 & 3.16 & -12.2 & 0.98 \\
& & Stat & 19 & 3.21 & -12.4 & 0.99 \\
Energy & All & Start & 19 & 3.13 & -12.0 & 0.99 \\
& LOW & End & 19 & 3.04 & -10.0 & 0.97 \\
& BG & End & 18 & 3.42 & -12.2 & 0.99 \\
& MI & End & 19 & 3.20 & -11.1 & 0.96 \\
& MIBG & End & 19 & 3.43 & -12.2 & 0.98 \\
\hline
\end{tabular}

For TL and mass, regressions were conducted both at the start and the end of the experiment. For the regressions of TL versus total energy, a regression was generated from a random subsample of largemouth bass at the start of the experiment, and thus represents all treatments (All). All models are of the form $\ln (Y)=a \ln (X)+\ln (b)$. All model parameters differed from 0 (t-tests, $\mathrm{p}=0.0001$ ). Total lengths within each model ranged $65-159 \mathrm{~mm}$.

\section{Results}

General patterns

Temperatures fluctuated widely between days $\left(\mathrm{ca} .6^{\circ} \mathrm{C}\right)$ early and late in the experiment (Figure 1), but remained $<10^{\circ} \mathrm{C}$. Water remained consistently below $4^{\circ} \mathrm{C}$ mid-experiment during early January through mid-February (Figure 1).

Analysis of covariance revealed that age- 0 large-mouth bass lost wet mass on average in all treatments (Tables 1 and 2). A lack of an interaction between time and length in each ANCOVA model revealed that largemouth bass of all lengths lost proportionally similar mass (Table 2). For energy loss, an interaction between time and length occurred in all but the MI treatment (Table 2). Slopes increased and intercepts declined because small individuals lost proportionally more energy than large counterparts (Table 1). In the MI treatment, average energy did not change during fall through spring at any length (Table 2).

Snails, oligochaetes, chironomids, and amphipods were the most abundant by mass in treatments with macroinvertebrates. Total macroinvertebrate mass in pools did not change through time (repeated measures ANOVA, time, $\mathrm{F}_{3,45}=0.91, \mathrm{p}=0.45$ ) but did differ among treatments (repeated measures ANOVA, treatment, $\mathrm{F}_{4,15}=4.36, \mathrm{p}=0.02$ ). This effect most likely occurred because macroinvertebrates were consistently more abundant in the macroinvertebrate treatments (MI and MIBG) than in the BG and LOW ones (Figure 2).

The proportion of empty stomachs within pools was unrelated to treatment across the 
four sampling dates (Figure 3; repeated measures ANOVA, treatment, $F_{3,10}=2.10, p=0.12$ ). However, a time effect (repeated measures ANOVA, time, $\mathrm{F}_{3,30}=5.23, \mathrm{p}=0.005$ ) revealed that the proportion of empty stomachs increased on the January sampling date when temperatures were consistently below $4^{\circ} \mathrm{C}$ (Figure 3). The contribution of fish, macroinvertebrates, and zooplankton to biomass in diets differed among treatments (Figure 4; MANOVA: treatment, Wilks lambda $\left.=0.154, \mathrm{~F}_{9,25}=3.15, \mathrm{p}=0.01\right)$. A univariate ANOVA revealed that this treatment effect was likely driven by the high biomass of fish in diets in the BG treatment (ANOVA for fish; $F_{3,15}=8.54, p=0.003$; Figure 4a). Neither the univariate ANOVA for macroinvertebrates nor zooplankton in diets was significant. The appearance of fish was unrelated to largemouth bass body size (G-test, $\mathrm{G}=0.05$, $\mathrm{df}=1, \mathrm{NS}$ ). Of the 17 largemouth bass that consumed fish, $41 \%$ and $59 \%$ of the largemouth bass were small $(<100 \mathrm{~mm})$ and large $(\geq 100 \mathrm{~mm})$, respectively, against the null expectation of $38 \%$ and $62 \%$ small and large.

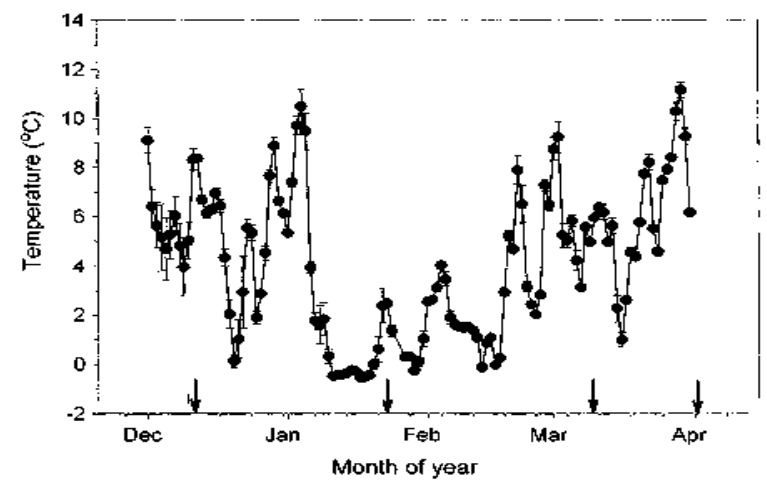

Figure 1. Mean \pm 1 SD daily temperature ( $\mathrm{N}=10$ observations/day) in two outdoor pools at the Ohio State University, Aquatic Ecology Laboratory during winter 1996-1997. Arrows indicate days when fish and macroinvertebrates were sampled.

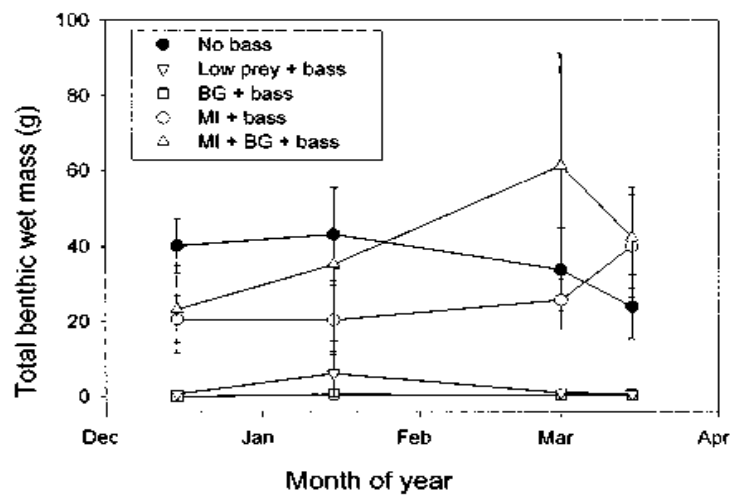

Figure 2. Mean $\pm 1 \mathrm{SE}(\mathrm{N}=4$ pools per treatment) benthic wet mass (extrapolated from cores to the entire bottom) in outdoor pools at the Ohio State University, Aquatic Ecology Laboratory during winter 1996-1997. Treatments are LOW, BG, MI, and MIBG. A fifth treatment in which no largemouth bass were present is labeled as No Bass. 


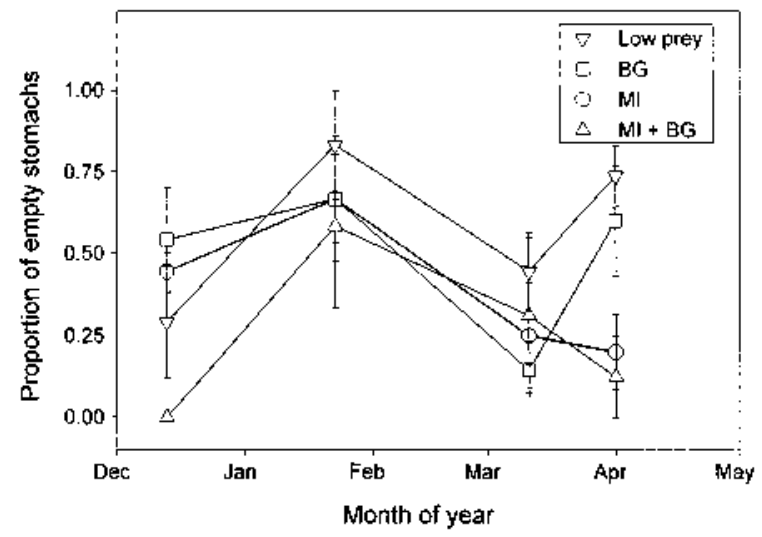

Figure 3. Mean \pm 1 SE proportion ( $\mathrm{N}=4$ pools per treatment) of largemouth bass with no food present in stomachs in outdoor pools at the Ohio State University, Aquatic Ecology Laboratory during winter 1996-1997. Treatments are the same as in Figure 2.

Table 2. Analysis of covariance (ANCOVA) incorporating the effect of total length (TL, $\mathrm{mm}$ ) and time (fall and spring) on mass ( $\mathrm{g}$ ) and total energy ( $\mathrm{kJ}$ ) of largemouth bass in outdoor pools at the Ohio State University, Aquatic Ecology Laboratory during winter 1996-1997.

\begin{tabular}{lllrl}
\hline $\begin{array}{l}\text { Dependent } \\
\text { variable }\end{array}$ & Treatment & Effect & F & p \\
\hline Mass & LOW & Time & 25 & 0.0001 \\
& & Length & 2738 & 0.0001 \\
& BG & Time & 9 & 0.003 \\
& & Length & 2174 & 0.0001 \\
& MI & Time & 4 & 0.07 \\
& & Length & 1504 & 0.0001 \\
& MIBG & Time & 18 & 0.0002 \\
& & Length & 4605 & 0.0001 \\
Energy & LOW & Time & 15 & 0.0005 \\
& & Length & 785 & 0.0001 \\
& BG & Time $*$ length & 12 & 0.002 \\
& & Time & 7 & 0.01 \\
& Length & 1384 & 0.0001 \\
& MI & Time $*$ length & 5 & 0.04 \\
& Time & 1 & 0.4 \\
& MIBG & Length & 806 & 0.0001 \\
& & Time & 6 & 0.02 \\
& Length & 1153 & 0.0001 \\
& Time $*$ length & 4 & 0.05 \\
\hline
\end{tabular}

Only significant interaction terms were included in ANCOVA models ( $\mathrm{p}<0.05$ )

Individual-based patterns

Although the ANCOVA revealed that average mass and energy declined during winter in all but the MI treatment, patterns of mass and energy content varied in unique ways among individuals within treatments. In the LOW treatment, all largemouth bass lost both wet mass and total energy (Figure 5a). The slope of this regression model was high, with individuals that lost 
about $30 \%$ wet mass also losing $60 \%$ of their total energy content. The regression model predicted that energy content should not change when wet mass did not change (i.e. the extrapolated regression line nearly intercepted $x=0, y=0$; Figure 5a), results nearly identical to those for starved largemouth bass in the previous overwinter pool experiment (Garvey et al. 1998a). In the BG treatment, all largemouth bass lost mass and energy content (Figure 5b). However, the slope of the regression was lower than that in the LOW treatment. Proportional changes in both wet mass and total energy ranged less than those in all the other treatments (Figure $5 \mathrm{~b}$ ). In the MI treatment, $31 \%$ of the largemouth bass gained wet mass, although total energy content declined (Figure 5c). The slope of this relationship was less than that of the bluegill-only and LOW treatments (Figure 5c). The range of change in wet mass and energy content was high (Figure 5c). In the MIBG treatment, change in total energy content did not vary with change in wet mass (Figure 5d). Only two of 20 largemouth bass gained wet mass, although energy content declined between 5\% and 50\% among individuals (Figure 5d).

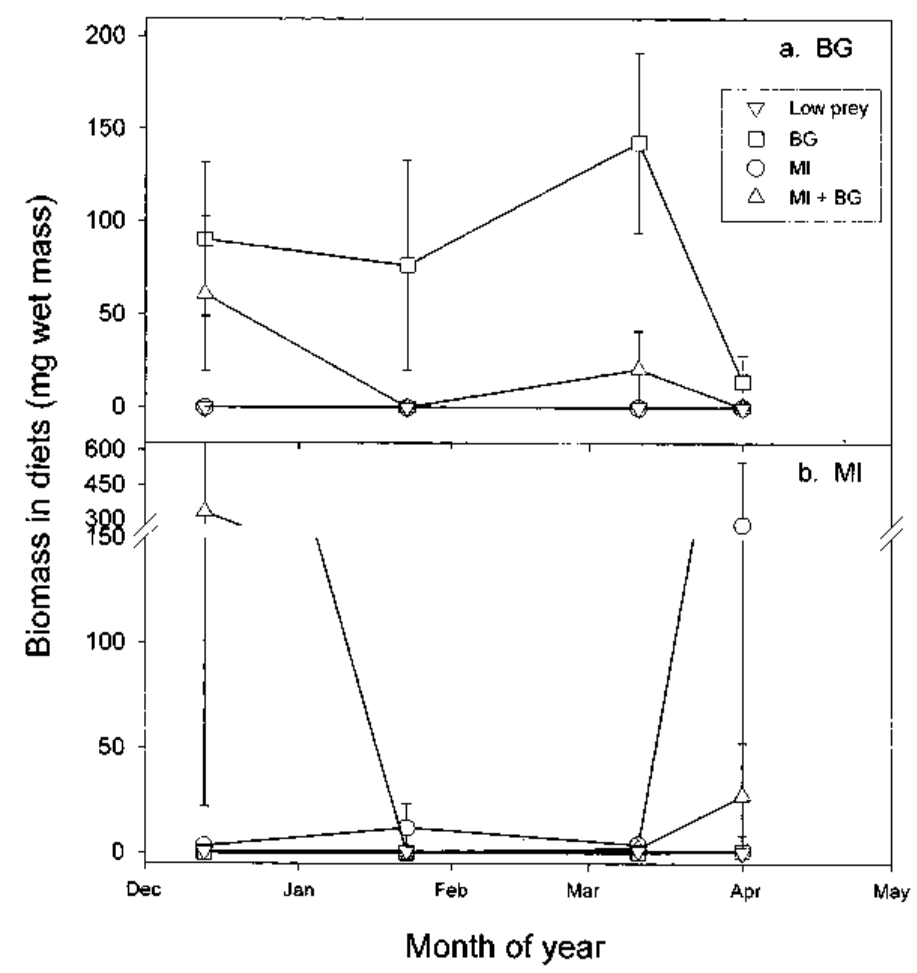

Figure 4. Mean \pm 1 SE biomass ( $N=4$ pools per treatment) of (a) BG and (b) $M I$ in stomachs of largemouth bass in outdoor pools at the Ohio State University, Aquatic Ecology Laboratory during winter 1996-1997. Treatments are the same as in Figure 2. Zooplankton were occasionally found in diets, although only contributing $<1 \mathrm{mg}$ on any date. Therefore, these values are not plotted. 


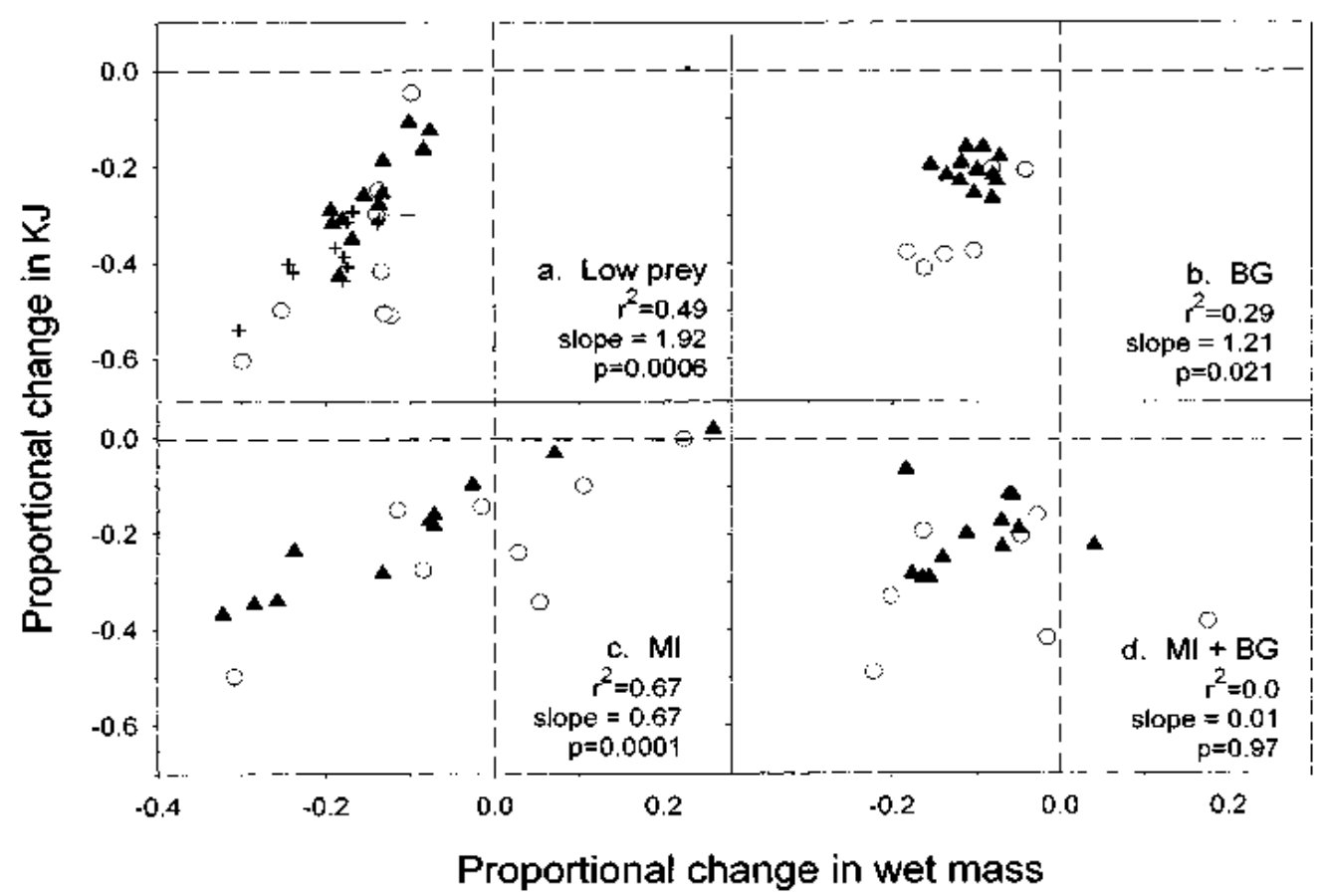

Figure 5. Relationship between proportional change in wet mass and energy content for individual largemouth bass in outdoor pools at the Ohio State University, Aquatic Ecology Laboratory during winter 19961997.Treatment descriptions are the same as in Figure 2. Horizontal and vertical dashed lines demarcate no change in energy content and wet mass, respectively. Symbols on each panel are open circle: largemouth bass <100 mm TL; closed triangle: largemouth bass $\geq 100 \mathrm{~mm}$ TL. In panel a, crossed symbols are for growth of starved largemouth bass in a similar pool experiment conducted during winter 1995-1996.

By pooling data across treatments, we explored how variation in growth changed with the foraging activity index among individuals. We then determined how patterns within each treatment contributed to the overall shape of the distribution. The 2DKS test revealed that the pooled bivariate distribution of the foraging activity index versus proportional change in wet mass was nonrandom (2DKS: $\mathrm{p}=0.017, \mathrm{D}=0.088$ ), with the point of maximum difference in the distribution occurring at 0.5 activity. Although the relationship between foraging activity and change in energy content did not differ from random (2DKS: $p=0.25, \mathrm{D}=0.057)$, the largest difference in the pooled distribution again occurred at 0.5 activity. We conclude that the pattern detected by the 2DKS for data combined across all treatments was likely an increase in variance among individuals in growth beyond 0.5 activity. To confirm, variance among individuals pooled across treatments was lower below 0.5 activity than above it for proportional change in mass (standard deviations: below $=0.05$, above $=0.11 ; \mathrm{F}_{61,9}=4.67, \mathrm{p}=0.017$ ) but not energy (standard deviations: below $=0.095$, above $=0.13 ; \mathrm{F}_{61,9}=1.91, \mathrm{p}=0.29$ ). T-tests revealed that mean proportional change in mass and energy content did not differ below or above 0.5 activity (mass means: below $=-0.131$, above $=-0.096$; energy content means: below $=-0.225$, above $=-$ 0.262).

Differences among treatments contributed to the overall shape of the bivariate distribution. A few individuals in all treatments but the BG one had low foraging activity index values (i.e. <0.5; Figure 6a-d). Although they did not consume prey, the growth of these 
individuals was often the same as or higher than largemouth bass that frequently had food in diets. The individual with the lowest combined change in mass and energy content was in the LOW treatment with foraging activity $=1$ (Figure 6a,e). High variance in growth at high foraging activity appeared to occur primarily in treatments with macroinvertebrates (Figure $6 \mathrm{c}, \mathrm{d}, \mathrm{g}, \mathrm{h})$ Although regressions revealed no functional linear relationships in most treatments, loss of energy of individuals in the LOW treatment increased with increasing foraging activity index (linear regression: slope $=-0.19, \mathrm{p}=0.08$; Figure $6 \mathrm{e}$ ).

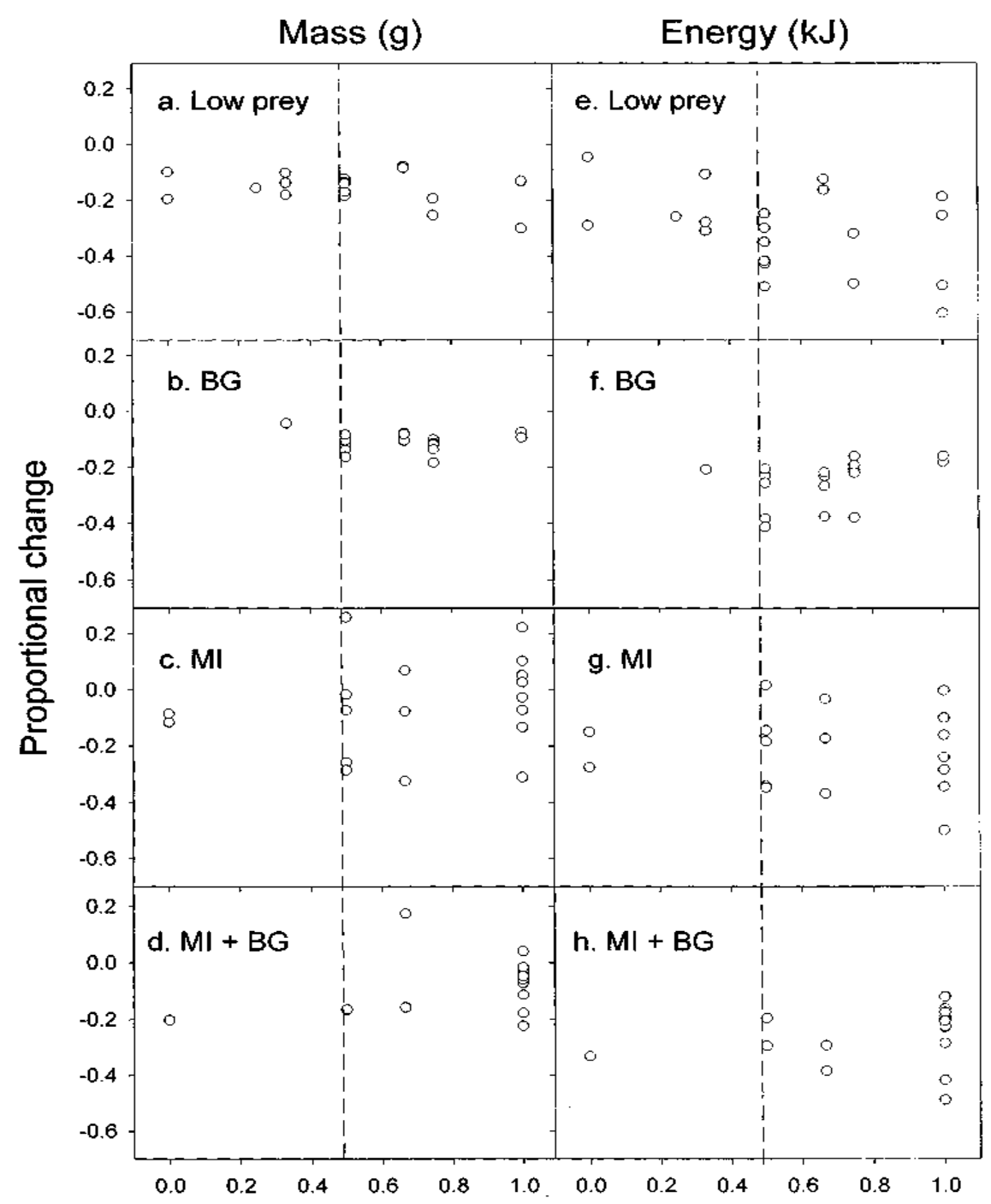

Foraging activity index

Figure 6. Change in mass and energy content as a function of an index of foraging activity (i.e. the proportion of sampling days that each individual largemouth bass contained food) in outdoor pools at the Ohio State University, Aquatic Ecology Laboratory during winter 1996-1997. Dashed lines in each panel denote the point of maximum difference in each bivariate distribution as determined by a 2DKS test for the data pooled across treatments. 
A post hoc analysis of capture success of large-mouth bass provided another index of activity. During the experiment, active individuals should be captured more frequently than inactive ones, presumably because inactive fish were concealed on pool bottoms. Further, active individuals should forage more frequently. Recall that on the last day of the experiment (April 1) when pools were drained, we retrieved almost all (95\%) of the largemouth bass. Proportion of individuals with prey in stomachs at this time increased with their frequency of capture during the experiment (Table 3; linear regression: $\mathrm{N}=4, \mathrm{r}^{2}=0.81, \mathrm{p}=0.065$ ). Of individuals captured only on one day, $43 \%$ had consumed prey as compared to $67 \%$ for those captured on all four sampling dates (Table 3), suggesting that individuals sampled less frequently were indeed less active and foraging less frequently than counterparts with prey in diets.

Table 3. Number of days that individual largemouth bass were successfully captured (4 maximum as an index of activity) versus the proportion of individuals with prey in stomachs (as a second index of activity) on the last day of an outdoor pool experiment at the Ohio State University, Aquatic Ecology Laboratory during winter 1996-1997.

\begin{tabular}{llc}
\hline $\begin{array}{l}\text { Number } \\
\text { of days } \\
\text { captured }\end{array}$ & $\begin{array}{l}\text { Propottion with } \\
\text { prey in stomach } \\
\text { on April I }\end{array}$ & $\begin{array}{l}\text { Number of } \\
\text { largemouth } \\
\text { bass }\end{array}$ \\
\hline 1 & 0.43 & 8 \\
2 & 0.42 & 19 \\
3 & 0.55 & 23 \\
4 & 0.67 & 15 \\
\hline
\end{tabular}

Increasing number of days captured infers greater activity during the experiment. Proportion of stomachs with prey indicates whether individuals were foraging or inactive. Results of linear regression of days captured versus proportion of empty stomachs: empty stomachs $=0.31+0.084$ [days] $(\mathrm{N}=4)$.

\section{Discussion}

Although investigators typically have considered winter a time of inactivity for fish (Crawshaw 1984), interactions between age-0 largemouth bass and their prey at the winter temperatures (i.e. consistently $<10^{\circ} \mathrm{C}$ ) in this pool experiment caused wet mass and energy content to change in treatment-specific ways. Below, we explore general mechanisms underlying patterns of survival, growth, and foraging among treatments. Because patterns of individual foraging and growth were unique among treatments, we also assess how individual foraging decisions during winter may influence growth and potentially survival, with implications for population dynamics.

\section{General patterns}

Winter survival often increases with increasing body size in age-0 fish (e.g. Post \& Evans 1989). This expectation was not upheld by our winter experiment. Survival was quite high in all treatments, regardless of body size. Similar results have emerged in other mid-latitude experiments (Garvey et al. 1998a), in which energy condition but not survival varied greatly among age-0 largemouth bass. Only when predators were present in lakes or ponds did we quantify disproportionately higher mortality of small individuals (Garvey et al. 1998a; also see Miranda \& Hubbard 1994). Hence, factors such as predation appear to be necessary to cause winter mortality at this latitude. 
Growth in many fishes declines during winter, with small fish more rapidly exhausting limited energy reserves than large counterparts (Post \& Evans 1989). Average mass and energy content did decline during winter in all treatments except the MI one. Also in partial agreement with expectations, loss of energy but not mass of largemouth bass in the LOW, BG, and MIBG treatments became less severe with increasing body size during winter. Energy depletion is often a better indicator of condition than mass loss because energy-dense fat declines while water content increases, causing mass to change less than energy content (Weatherley \& Gill 1987).

Interactions between body size and prey availability may have affected size-dependent patterns of growth among treatments. Size was likely unrelated to growth in the MI treatment because small individuals had more foraging opportunities for small macro-invertebrates than those in other treatments. In the BG treatment, energy depletion increased with declining size because small individuals were likely less successful at capturing bluegill prey (see Christensen 1996). In the MIBG treatment, competition between small largemouth bass and bluegill for invertebrates may have reduced their foraging success, leading to observed size-dependent patterns (Olson et al. 1995). Although interspecific competition for particular prey sizes or taxa may have occurred, overall macroinvertebrate abundance did not differ between MI treatments or during the winter, suggesting that overall food availability probably was not limiting. In summary, these results support the hypothesis that prey assemblage structure influences patterns of size-dependent growth during winter. If energy condition influences important factors such as susceptibility to predation, competitive ability, or disease resistance in spring, then interactions with prey during winter may influence size-dependent survival during the second year of life.

Many studies have demonstrated that age-0 large-mouth bass switch from macroinvertebrate to fish prey when fish prey become available by late summer and fall (Olson 1996a,b, Garvey et al. 1998b). Presumably, this occurs because fish are more energy dense, incurring greater growth benefits in age- 0 piscivores. In contrast to this hypothesis, age- 0 largemouth bass preferentially consumed macroinvertebrates over bluegills during winter when both prey were present. Thus, macroinvertebrates were either more available or easier to capture than bluegill. Variability in macroinvertebrates rather than fish among systems may determine patterns of energy depletion and ultimately survival of age- 0 fish during winter.

The variable temperatures in pools during winter affected patterns of foraging through time. Foraging of age-0 largemouth bass declined as temperatures in pools declined. Similar reductions in foraging activity (Fullerton et al. 2000) and subsequent growth (Garvey et al. 1998) regardless of prey availability have occurred in other winter experiments with age-0 largemouth bass (Crawshaw 1984). Hence, the influence of prey structure on largemouth bass foraging behavior and growth should decline as the duration of cold winter temperatures increases. From this, we predict that the sensitivity of growth and perhaps survival of age- 0 largemouth bass to prey assemblage structure should decline with increasing latitude.

\section{Individual decisions and winter dynamics}

If largemouth bass were behaving in a uniform fashion during winter, then patterns of growth should be uniform as well. Mass-balance bioenergetics predicts that individuals within a population of the same sizes with similar ration and activity should grow at equivalent rates (Rice et al. 1984). Clearly, patterns of growth within each treatment departed greatly from this model. Metabolic rate, energy intake, or activity differed substantially among individuals to generate this variability. Wright et al. (1999) found that traditional bioenergetics models overestimated consumption of age-0 large-mouth bass during winter (based on observed growth), 
particularly when ration was restricted. They hypothesized that this discrepancy arose because largemouth bass reduce metabolic rates to offset costs of winter fasting. Perhaps, individual variation in metabolic responses affected patterns of growth in our experiment. Inferring activity from individual-specific diet data revealed that individuals varied in their foraging activity with different consequences for growth. Although most individuals foraged frequently in all treatments, all treatments but the BG one included some individuals that rarely foraged. The implications of these differences in apparent foraging activity are compelling.

The relatively low variance in growth among large-mouth bass that foraged infrequently across all treatments indicated that they minimized metabolic costs by rarely searching for prey, relying solely on energy reserves. Patterns among individuals that foraged actively were less consistent, although the average losses were similar to those of counterparts that foraged rarely. We hypothesize that this increased variance among active foragers was due to differences in foraging success. Individuals that consumed energy-dense prey maintained or increased mass with low energy loss. Counterparts that foraged with poor success (e.g. particularly those in the LOW treatment in which large, energy-rich prey were largely absent) were forced to use energy reserves to offset activity costs. Interestingly, all individuals confronted solely with fish prey in the BG treatment foraged sufficiently frequently to maintain loss of mass and energy near the average. This tactic appeared to have the same consequences for growth as rarely foraging during winter.

An individual-based approach is important when events differ dramatically among individuals within a population (Crowder et al. 1992). This phenomenon is common very early in the life of fishes (i.e. larval stage) in which individual variation in foraging success or escape from predation strongly influences survival to later life stages (Miller et al. 1988). Factors affecting individual responses during winter are not well understood. Individual largemouth bass in a previous winter pool experiment with fathead minnows Pimephales promelas consistently grew during winter (Garvey et al. 1998a). In our pool experiment, bluegills were less abundant and potentially more difficult to capture. Even so, bluegill prey reduced variation in mass and energy loss. Macroinvertebrate prey increased variation in winter growth, potentially due to the rarity of large, energy-rich prey in the prey assemblage. Mechanistic research exploring how individual behavioral and energetic responses vary as a function of temperature, prey type, and energetic condition is necessary to improve resolution.

Although many questions remain, it is apparent that winter is not a time of inactivity for age-0 largemouth bass. Rather, the nature of the prey assemblage, winter temperature, and perhaps energy reserves profoundly affect patterns of spring condition among individuals. Without an improved understanding of the interplay among these factors, it will be difficult to accurately predict the recruitment of largemouth bass and other temperate-latitude, warm-water fishes.

\section{Acknowledgements}

We thank Kristen Ferry, Kristin Field, and Rick Ginsberg for their technical assistance. This research was funded by National Science Foundation grant DEB 9407859 to R.A.S. and Federal Aid in Sport Fish Restoration Project F-69-P, administered jointly by the U.S. Fish and Wildlife Service and Ohio Division of Wildlife.

\section{References cited}

Adams, S.M., R.B. McLean \& M.M. Huffman. 1982. Structuring of a predator population 
through temperature-mediated effects on prey availability. Can. J. Fish. Aquat. Sci. 39: $1175-1184$.

Adams, S.M., R.B. McLean \& J.A. Parrotta. 1982b. Energy partitioning in largemouth bass under conditions of seasonally fluctuating prey availability. Trans. Amer. Fish. Soc. 111: 549-558.

Baldwin, C.M., D.A. Beauchamp \& J.J. Van Tassell. 2000. Bioenergetic assessment of temporal food supply and consumption demand by salmonids in the Strawberry Reservoir food web. Trans. Amer. Fish. Soc. 129: 429-450.

Brown, J.H. 1995. Organisms and species as complex adaptive systems: Linking the biology of populations with the physics of ecosystems. pp. 16-24. In: C.G. Jones \& J.H. Lawton (ed.) Linking Species and Ecosystems, Chapman and Hall, New York.

Cargnelli, L.M. \& M.R. Gross. 1997. Fish energetics: Larger individuals emerge from winter in better condition. Trans. Amer. Fish. Soc. 126: 153-156.

Chambers, R.C. \& E.A. Trippel. 1997. Early life history and recruitment: Legacy and challenges. pp. 516-549. In: R.C. Chambers \& E.A. Trippel (ed.) Early Life History and Recruitment in Fish Populations, Chapman and Hall, New York.

Christensen, B. 1996. Predator foraging capabilities and prey antipredator behaviours: Preversus postcapture constraints on size-dependent predator-prey interactions. Oikos 76: 368-380.

Cowan, J.H., K.A. Rose \& D.R. DeVries. 2000. Is density-dependent growth in young-of-theyear fishes a question of critical weight? Rev. Fish Biol. Fish. 10: 61-89.

Crawshaw, L.I. 1984. Low temperature dormancy in fish. Amer. J. Physiol. 246: 479-486.

Crowder, L.B., J.A. Rice, T.J. Miller \& E.A. Marschall. 1992. Empirical and theoretical approaches to size-based interactions and recruitment variability in fishes. pp. 237-255. In: D.L. DeAngelis \& L.J. Gross (ed.) Individual-based Models and Approaches in Ecology, Chapman and Hall, London.

Dumont, H.J., I. Van de Velde \& S. Dumont. 1975. The dry weight estimates of biomass in selection of Cladocera, Copepoda and Rotifera from the plankton, periphyton, and benthos of continental waters. Oecologia 19: 75-97.

Fasano, G. \& A. Franceschini. 1987. A multidimensional version of the Kolmogorov-Smirnov test. Monthly Notices of the Royal Astronomical Society 225: 155-170.

Foy, R.J. \& A.J. Paul. 1999. Winter feeding and changes in somatic energy content of age-0 Pacific herring in Prince William Sound, Alaska. Trans. Amer. Fish. Soc. 128: 11931200.

Fullerton, A.H., J.E. Garvey, R.A. Wright \& R.A. Stein. 2000. Overwinter growth and survival of largemouth bass: Interactions among size, food, origin, and winter duration. Trans. Amer. Fish. Soc. 129: 1-12.

Garvey, J.E., R.A. Wright \& R.A. Stein. 1998a. Overwinter growth and survival of age-0 largemouth bass: Revisiting the role of body size. Can. J. Fish. Aquat. Sci. 55: 24142424.

Garvey, J.E., N.A. Dingledine, N.S. Donovan \& R.A. Stein. 1998b. Exploring spatial and temporal variation within reservoir food webs: Predictions for fish assemblages. Ecol. Appl. 8: 104-120.

Garvey, J.E., E.A. Marschall \& R.A. Wright. 1998c. From star charts to stoneflies: Detecting relationships in continuous bivariate data. Ecology 79: 442-447.

Gutreuter, S.J., \& R.O. Anderson. 1985. Importance of body size to the recruitment process in 
largemouth bass. Trans. Amer. Fish. Soc. 114: 317-327.

Judson, O.P. 1994. The rise of the individual-based model in ecology. Trends Ecol. Evol. 9: 914.

Krebs, J.R. \& A. Kacelnik. 1984. Decision-making. pp. 105-136. In: J.R. Krebs \& N.B. Davies (ed.) Behavioural Ecology, Sinauer Associates, Sunderland, MA.

Miller, T.J., L.B. Crowder, J.A. Rice \& E.A. Marschall. 1988. Larval size and recruitment mechanisms in fishes: Toward a conceptual framework. Can. J. Fish. Aquat. Sci. 45: 1657-1670.

Miranda, L.E. \& W.D. Hubbard. 1994. Winter survival of age-0 largemouth bass relative to size, predators and shelter. North Amer. J. Fish. Manage. 14: 790-796.

Olson, M.H. 1996a. Ontogenetic niche shifts in largemouth bass: Variability and consequences for first-year growth. Ecology 77: 179-190.

Olson, M.H. 1996b. Predator-prey interactions in size-structured fish communities: Implications of prey growth. Oecologia 108: 757-763.

Olson, M.H., G.G. Mittelbach \& C.W. Osenberg. 1995. Competition between predator and prey: Resource-based mechanisms and implications for stage-structured dynamics. Ecology 76: 1758-1771.

Post, J.R. \& D.O. Evans. 1989. Size-dependent overwinter mortality of young-of-year yellow perch (Perca flavescens): Laboratory, in situ enclosure, and field experiments. Can. J. Fish. Aquat. Sci. 46: 1958-1968.

Press, W.H., S.A. Teukolsky, W.T. Vetterling \& B.P. Flannery. 1992. Numerical Recipes in C: The Art of Scientific Computing, Cambridge University Press, New York.

Rice, J.A. \& P.A. Cochran. 1984. Independent evaluation of a bioenergetics model for largemouth bass. Ecology 65: 732-739.

Seaburg, K.G. 1957. A stomach sampler for live fish. Progressive Fish Culturist 19: 137-139. Shul'man, G.E. 1974. Life Cycles of Fish, John Wiley and Sons Inc., New York, 258 pp. Smallwood, P.D.\&R.V. Cartar. 1996. Risk sensitivity in behavior: Where are we now? Introduction to the Symposium. Amer. Zool. 36: 389-391.

Smock, L.A. 1980. Relationships between body size and biomass of aquatic insects. Freshwa. Biol. 10: 375-383.

Sokal, R.R. \& F.J. Rohlf. 1995. Biometry: The Principles and Practice of Statistics in Biological Research, W.H. Freeman and Company, New York.

Toneys, M.L., and D.W. Coble. 1979. Size-related, first winter mortality of freshwater fishes. Trans. Amer. Fish. Soc. 108: 415-419.

Weatherley, A.H. \& H.S. Gill. 1987. The Biology of Fish Growth. Academic Press, London, 443 pp.

Wright, R.A., J.E. Garvey, A.H. Fullerton \& R.A. Stein. 1999. Using bioenergetics to explore how winter conditions affect growth and consumption of age-0 largemouth bass. Trans. Amer. Fish. Soc. 128: 603-612. 